\title{
Repeat dosing of rocuronium-sugammadex: unpredictable
}

\author{
Yoon-Hee Kim
}

Department of Anesthesiology and Pain Medicine, Chungnam National University College of Medicine, Daejeon, Korea

Like many other great discoveries, sugammadex was discovered incidentally. Anton Bom, a pharmaceutical chemist employed by Organon, Inc., was attempting to identify a new solvent that could enhance the solubility of rocuronium bromide. Instead, he was the first to discover that long-term use of cyclodextrin as a solubilizing agent offset the potency of rocuronium. The three-dimensional structure of cyclodextrin resembles a hollow or doughnut. The structure contains a hydrophobic cavity and hydrophilic exterior because of the presence of polar hydroxyl groups. Hydrophobic interactions trap the drug within the cyclodextrin cavity, resulting in the formation of a water-soluble guest-host complex. Sugammadex was developed by adding negatively charged carboxyl groups to each end of the side chain, thus increasing the electrostatic binding force with the positively charged rocuronium, and by adding eight side chains to encapsulate the relatively large-sized rocuronium [1,2]. Interestingly, sugammadex acts much like Febreze, an odor-controlling agent commonly used within the home. Sugammadex, the first selective relaxant-binding agent, acts by tightly binding to steroidal neuromuscular blocking agents through intermolecular forces and thermodynamic and hydrophobic interactions [3]. Introduction of sugammadex to the field of anesthesia was termed "a milestone" [3], "a revolutionary approach" [4], and "a turning point in the practice of anesthesiology" [5]. Anesthesiologists were enormously enthusiastic about this new drug. In fact, since the emergence of sugammadex, no revolutionary novel drugs have been developed for the last 20 years. Additionally, because of the many limitations of the anticholinesterases commonly used as reversal agents after the administration of neuromuscular blockers, anesthesiologists were in need of a drug that could reverse neuromuscular blockade in a short period of time.
After sugammadex is injected, it rapidly binds with free rocuronium molecules in the plasma, leading to a decrease in the rocuronium plasma concentration. Thus, a rocuronium concentration gradient is formed between the plasma and neuromuscular junction, and rocuronium is released from the neuromuscular junction to the plasma, where it can also bind with sugammadex [2]. Available evidence suggests that the rocuronium-sugammadex complex remains stable over time. This complex exists in equilibrium with a very low dissociation rate (dissociation constant $\mathrm{Kd}=0.1 \times 10^{-6} \mathrm{M}$ ) because of the strong binding $[3,6]$.

The molecular weight of sugammadex is $2,178 \mathrm{Da}$, while that of rocuronium is $610 \mathrm{Da}$; the two molecules bind in a $1: 1$ molar ratio. Thus, precisely $3.57 \mathrm{mg}$ of sugammadex are required to bind $1.00 \mathrm{mg}$ of rocuronium $[3,6]$. Accordingly, we can conclude that effective reversal is guaranteed by injection of $2.4 \mathrm{mg} / \mathrm{kg}$ of sugammadex at any time after injection of $0.6 \mathrm{mg} / \mathrm{kg}$ of rocuronium [7]. In the dose range of 0.1 to $16.0 \mathrm{mg} / \mathrm{kg}$, the pharmacokinetics of sugammadex show a linear, dose-dependent relationship [2].

Sugammadex $(0.1-8.0 \mathrm{mg} / \mathrm{kg})$ has a clearance rate of $88 \mathrm{ml} / \mathrm{min}$, elimination half-life of $1.8 \mathrm{~h}$, and distribution volume of 11 to $14 \mathrm{~L}[8,9]$. Approximately $75 \%$ of the dose is eliminated renally; $59-80 \%$ of the dose is excreted renally in the first $24 \mathrm{~h}$ after administration [8].

After encapsulation by sugammadex, rocuronium is confined to the space in which sugammadex resides, and urinary excretion is the main route of elimination of the sugammadex-rocuronium complex. Administration of sugammadex diverts the elimination of rocuronium from its normal primary pathway of hepatic clearance to renal clearance [8].

Sugammadex is a very safe drug with almost no serious adverse

Corresponding author: Yoon-Hee Kim, M.D., Department of Anesthesiology and Pain Medicine, Chungnam National University College of Medicine, 282, Munhwa-ro, Jung-gu, Daejeon 301-721, Korea. Tel: 82-42-280-7846, Fax: 82-42-220-7968, E-mail: yhkim040404@gamil.com (c) This is an open-access article distributed under the terms of the Creative Commons Attribution Non-Commercial License (http:// creativecommons.org/licenses/by-nc/3.0/), which permits unrestricted non-commercial use, distribution, and reproduction in any medium, provided the original work is properly cited. 
effects [10]. The known adverse effects include slight coughing, movement, an altered taste sensation in the mouth, transient prolongation of the QT interval, hypersensitivity, and a shortterm $(<30 \mathrm{~min})$ prolongation of the activated partial thromboplastin time [10].

Use of sugammadex has other drawbacks, such as its high cost. It appears that the manufacturer of sugammadex made a strategic marketing decision to secure a high profit margin on a low volume of sales [11]. Another drawback is the lack of studies and clinical reports on reparalysis after the reversal of neuromuscular blockade with sugammadex or studies on the repetitive injection of sugammadex after reinjection of a neuromuscular blocker. Because of this scarcity of studies and clinical reports, there is no clear information regarding the proper dose, time of drug administration, time of onset, and duration of action of each drug for patients who require a second administration. This may lead to risks including residual or insufficient neuromuscular blockade.

Although uncommon, patients may require anesthesia and tracheal intubation in the immediate postoperative period or within a few hours of reversal of a block. The use of neuromuscular blockers must be considered carefully if the block has been reversed with sugammadex. There are three management options in such cases: administration of succinylcholine; administration of a benzylisoquinoline neuromuscular blocker (atracurium, cis-atracurium, or mivacurium); or a second administration of rocuronium [12]. Even now, discussion regarding the optimal choice is ongoing $[13,14]$. Bom et al. [15] reported a slight delay in the onset time but a normal speed of recovery when succinylcholine was administered $3 \mathrm{~min}$ after reversing the rocuroniuminduced neuromuscular blockade with sugammadex in a guinea pig. Benzylisoquinoline neuromuscular blockers cannot be encapsulated by sugammadex because of their large, bulky size and therefore cannot be reversed [16]. Because sugammadex is unable to bind to benzylisoquinoline neuromuscular blockers, it is possible that normal neuromuscular blockade can be induced even after previous sugammadex administration. Unfortunately, studies on benzylisoquinoline neuromuscular blockers in this context are limited, and additional studies on the changes in the pharmacokinetics are required. Another disadvantage of benzylisoquinoline neuromuscular blockers is that they cannot be reversed by sugammadex. Finally, in this issue of the Korean Journal of Anesthesiology, Lee et al. [17] presented a case of a 21-year-old male patient who required a reoperation because of post-tonsillectomy hemorrhage. The patient required four reoperations during the first $12 \mathrm{~h}$ postoperatively because of repeated postoperative bleeding. Rocuronium was used in all four operations, while sugammadex was administered during the last three operations.
When reparalysis is required, it is encouraging that sugammadex can reverse neuromuscular blockade after the reuse of rocuronium. However, the onset time and duration of action of the second dose of rocuronium are unpredictable due to several: the dose of rocuronium, the previous dose of sugammadex, and the duration of time between drug injections, among others. It is recommended that re-injection of rocuronium $(0.6 \mathrm{mg})$ should be performed $6 \mathrm{~h}$ after previous sugammadex administration, which is three folds of the elimination half-life of the sugammadex [18]. However, the effects of reinjected rocuronium depend on the plasma concentration of circulating free rocuronium. Thus, it is possible to induce a complete neuromuscular block by increasing the second rocuronium dose even immediately after sugammadex administration. Cammu et al. [18] reported that complete neuromuscular blockade can be induced by reinjection of $1.2 \mathrm{mg} / \mathrm{kg}$ of rocuronium $5 \mathrm{~min}$ after injecting 4.0 $\mathrm{mg} / \mathrm{kg}$ of sugammadex. However, the duration of neuromuscular blockade decreases to $25 \mathrm{~min}$. Cammu et al. [18] also reported that when a repeat dose of $1.2 \mathrm{mg} / \mathrm{kg}$ of rocuronium is injected $30 \mathrm{~min}$ after $4.0 \mathrm{mg} / \mathrm{kg}$ of sugammadex, the onset time is less than $2 \mathrm{~min}$; on the other hand, the onset time reaches 4.25 min when $1.2 \mathrm{mg} / \mathrm{kg}$ of rocuronium is administered within 25 min of $4.0 \mathrm{mg} / \mathrm{kg}$ of sugammadex. This implies that the duration of time after the previous sugammadex administration is closely related to the dose requirement for repeated complete neuromuscular blockade, onset time, and duration of action of rocuronium. However, there are no accurate data regarding this relationship. Both the duration and dose of previously administered sugammadex have been shown to affect the required dose of repeatedly administered rocuronium.

de Boer et al. [19] suggested using rocuronium doses of 1.0 and $1.5 \mathrm{mg} / \mathrm{kg}$ when sugammadex doses of 2.0 and $4.0 \mathrm{mg} / \mathrm{kg}$, respectively, have been used for reversal of a block induced by $0.6 \mathrm{mg} / \mathrm{kg}$ of rocuronium in the immediate postoperative period. They also stated that when $8 \mathrm{mg} / \mathrm{kg}$ of sugammadex is administered, the required dose of rocuronium for reparalysis is $>2 \mathrm{mg} / \mathrm{kg}$. Thus, higher doses of rocuronium are required after higher doses of previous sugammadex, and even higher doses of sugammadex are required to reverse the reinjected rocuronium.

Therefore, it is important to avoid unnecessarily large doses of sugammadex for patients who are at risk of re-operation or reintubation in the immediate postoperative period. Use of the most efficient and smallest dose of sugammadex can be accomplished by performing neuromuscular monitoring in these patients. Even more importantly, we are in desperate need of an extensive and reliable study of the effects of repeated administration of rocuronium and sugammadex on the pharmacokinetics and pharmacodynamics of both agents. 


\section{References}

1. Bom A, Hope F, Rutherford S, Thomson K. Preclinical pharmacology of sugammadex. J Crit Care 2009; 24: 29-35.

2. Akha AS, Rosa J 3rd, Jahr JS, Li A, Kiai K. Sugammadex: cyclodextrins, development of selective binding agents, pharmacology, clinical development, and future directions. Anesthesiol Clin 2010; 28: 691-708.

3. Naguib M. Sugammadex: another milestone in clinical neuromuscular pharmacology. Anesth Analg 2007; 104: 575-81.

4. Kopman AF. Sugammadex: a revolutionary approach to neuromuscular antagonism. Anesthesiology 2006; 104: 631-3.

5. Miller RD. Sugammadex: an opportunity to change the practice of anesthesiology? Anesth Analg 2007; 104: 477-8.

6. Bom A, Bradley M, Cameron K, Clark JK, Van Egmond J, Feilden H, et al. A novel concept of reversing neuromuscular block: chemical encapsulation of rocuronium bromide by a cyclodextrin-based synthetic host. Angew Chem Int Ed Engl 2002; 41: 266-70.

7. Donati F. Sugammadex: an opportunity for more thinking or more cookbook medicine? Can J Anaesth 2007; 54: 689-95.

8. Gijsenbergh F, Ramael S, Houwing N, van Iersel T. First human exposure of Org 25969, a novel agent to reverse the action of rocuronium bromide. Anesthesiology 2005; 103: 695-703.

9. Gillespie JI, Harvey IJ, Drake MJ. Agonist- and nerve-induced phasic activity in the isolated whole bladder of the guinea pig: evidence for two types of bladder activity. Exp Physiol 2003; 88: 343-57.

10. Mirakhur RK. Sugammadex in clinical practice. Anaesthesia 2009; 64 Suppl 1: 45-54.

11. Yamakage M, Namiki A. Anesthetic practice in Japan: past, present, and future. J Anesth 2007; 21: 390-5.

12. Schaller SJ, Fink H. Sugammadex as a reversal agent for neuromuscular block: an evidence-based review. Core Evid 2013; 8: 57-67.

13. Fabregat-López J, Veiga-Ruiz G, Dominguez-Serrano N, García-Martinez MR. Re-establishment of neuromuscular block by rocuronium after sugammadex administration. Can J Anaesth 2011; 58: 658-9.

14. Harris P. Unexpected failure of rocuronium-mediated neuromuscular blockade. Anaesthesia 2011; 66: 525.

15. Bom A, Hope F. Neuromuscular block induced by rocuronium and reversed by the encapsulating agent Org25969 can be re-established using the non-sterodial neuromuscular blockers succinylcholine and cis-atracurium. Eur J Anaesth 2005; 22 (Suppl 34): 120.

16. de Boer HD, van Egmond J, van de Pol F, Bom A, Booij LH. Sugammadex, a new reversal agent for neuromuscular block induced by rocuronium in the anaesthetized Rhesus monkey. Br J Anaesth 2006; 96: 473-9.

17. Lee HJ, Kim KS, Kim TY, Lee JH, Jeong M. The use of 3 sugammadex out of 5 reversal of during recovery of rocuronium-induced neuromuscular blockade in a patient with post-tonsillectomy hemorrhage -a case report-. Korean J Anesthsiol 2014; 66: 43-7.

18. Cammu G, de Kam PJ, De Graeve K, van den Heuvel M, Suy K, Morias K, et al. Repeat dosing of rocuronium $1.2 \mathrm{mg} \mathrm{kg}^{-1}$ after reversal of neuromuscular block by sugammadex $4.0 \mathrm{mg} \mathrm{kg}^{-1}$ in anaesthetized healthy volunteers: a modelling-based pilot study. Br J Anaesth 2010 ; 105: 487-92.

19. de Boer HD, Driessen JJ, van Egmond J, Booij LH. Non-steroidal neuromuscular blocking agents to re-establish paralysis after reversal of rocuronium-induced neuromuscular block with sugammadex. Can J Anaesth 2008; 55: 124-5. 